\title{
Effects of air-polishing powders on color stability of composite resins
}

\author{
Ahmet Umut GÜLER , Ibrahim DURAN² , Ali Çağin YÜCEL ${ }^{3}$, Pelin ÖZKAN
}

1- DDS, PhD, Associate Professor, Department of Prosthodontics, Faculty of Dentistry, Ondokuz Mayıs University, Samsun, Turkey.
2- DDS, Research Assistant, Department of Prosthodontics, Faculty of Dentistry, Ondokuz Mayıs University, Samsun, Turkey.
3- DDS, PhD, Associate Professor, Department of Restorative Dentistry, Faculty of Dentistry, Ondokuz Mayıs University, Samsun, Turkey.
4- DDS, PhD, Associate Professor, Department of Prosthodontics, Faculty of Dentistry, Ankara University, Ankara, Turkey.

Corresponding address: Dr. Ahmet Umut GÜLER - Ondokuz Mayıs University, Faculty of Dentistry - Department of Prosthodontics - 55139 - Kurupelit Samsun - Turkey - Fax: 00903624576032 - e-mail: auguler@omu.edu.tr

Received: September 24, 2009 - Modification: April 30, 2010 - Accepted: May 25, 2010

\section{ABSTRACT}

\begin{abstract}
$\mathrm{O}$ bjectives: The purpose of this study was to investigate the effect of different airpolishing powders on the color stability of different types of composite resin restorative materials. Material and methods: Thirty cylindrical specimens $(15 \times 2 \mathrm{~mm})$ were prepared for each of 7 composite resin restorative materials. All specimens were polished with a series of aluminum oxide polishing discs (Sof-Lex). The prepared specimens of each composite resin were randomly divided into 3 groups of 10 specimens each, for control (Group-C) and two air-powder applications (Group-CP: Cavitron Prophy-Jet; Group-PS: Sirona ProSmile prophylaxis powder). A standard air-polishing unit (ProSmile Handly) was used. All specimens were air-powdered for $10 \mathrm{~s}$ at 4-bar pressure. The distance of the spray nosel from the specimens was approximately $10 \mathrm{~mm}$ and angulation of the nosel was $90^{\circ}$. Specimens were stored in $100 \mathrm{~mL}$ of coffee (Nescafe Classic) for $24 \mathrm{~h}$ at $37^{\circ} \mathrm{C}$. Color measurement of all specimens was recorded before and after exposure to staining agent with a colorimeter (Minolta CR-300). Color differences $\left(\Delta \mathrm{E}^{*}\right)$ between the 2 color measurements (baseline and after $24 \mathrm{~h}$ storage) were calculated. The data were analyzed with a 2-way ANOVA test, and mean values were compared by the Tukey HSD test ( $p \leq 0.05)$. Results: According to the 2-way ANOVA results, composite resin restorative materials, air-polishing powders, and their interaction were statistically significant $(p<0.05)$ For Aelite Aesthetic Enemal, Filtek Z250, Grandio, CeramX Mono, and Quixfil composite resin restorative materials, no significant difference was observed between Group-PS and Group-CP $(p>.05)$ and these groups demonstrated the highest $\triangle E^{*}$ values. For Filtek Silorane and IntenS, the highest $\Delta \mathrm{E}^{*}$ values were observed in Group-PS. The lowest $\Delta \mathrm{E}^{*}$ values for all composite resin groups were observed in Group-C. When comparing the 7 composite resin restorative materials, Aelite Aesthetic Enemal demonstrated significantly less $\Delta \mathrm{E}^{*}$ values than the other composite resins tested. The highest $\Delta \mathrm{E}^{*}$ values were observed in Quixfil. Conclusion: Except for Quixfil, all control groups of composite resins that were polished Sof-Lex exhibited clinically acceptable $\Delta \mathrm{E}$ values $(<3.7)$. Air-polishing applications increased the color change for all composite resin restorative materials tested. Composite restorations may require re-polishing after air-polishing.
\end{abstract}

Key words: Composite resins. Air abrasion. Polishing. Sodium bicarbonate. Color.

\section{INTRODUCTION}

Composite resins are widely used for the direct restoration of both anterior and posterior teeth because of the esthetic, physical, and mechanical properties of these materials. A resin composite is composed of 4 major components: organic polymer matrix, inorganic filler particles, coupling agents, and the initiator-accelerator system. The organic polymer matrix in most commercial composites today is either an aromatic or urethane diacrylate oligomer. The 3 most common oligomers that have been used in dental composites are bisphenol- A-diglycidyl-ether-methacrylate (bis- 
GMA), urethane dimethacrilate (UDMA), and triethylene glycol dimethacrylate (TEGDMA) 22 . In addition, siloranes have been suggested as alternatives to methacrylates as matrix resin components for dental composite because of their physical properties ${ }^{10}$. Composite resins have been classified according to various characteristics such as filler type, filler distribution, average particle size of filler, and physical and mechanical properties of the materials. Currently, three categories have been proposed for widely used composite resins: microfilled, microhybrid, and nanocomposite ${ }^{24}$.

Discoloration of restorative materials may lead to patient dissatisfaction and additional expense for replacement. Failure or success of any esthetic restoration depends first on the color match and then on the color stability of the materials. The degree of color change can be affected by a number of factors including diet ${ }^{8}$ and surface roughness ${ }^{26}$.

The quantitative evaluation of color difference $\left(\Delta \mathrm{E}^{*}\right)$ with a colorimeter confers advantages such as repeatability, sensitivity, and objectivity, despite some limitations ${ }^{28}$. In principle, if a material is completely color stable, no color difference will be detected after its exposure to the testing environment $\left(\Delta \mathrm{E}^{*}=0\right)$. Various studies have reported different thresholds of color difference values above which the color change is perceptible by the human eye. $A \Delta E^{*}$ value of 3.7 or less is considered to be clinically acceptable ${ }^{14,18}$.

Hygiene maintenance therapy is an integral part of restorative and periodontal treatment. The removal of stains and plaque from all accessible tooth surfaces is a routine part of the maintenance appointment ${ }^{29}$. The conventional rubber cup prophylaxis and the air-powder polishing system are both effective professional techniques for plaque and stain removal, without detrimental effects on tooth structure and gingival tissues when correctly used. Since its introduction to the dental marketplace in 1977, air-powder polishing systems have been effective at removing stain and plaque $^{5}$. The designs of the various air-powder polishing systems, such as Sirona ProSmile Handly, use a mixture of air, water and sodium bicarbonate to deliver a controlled stream of sodium bicarbonate particles to the tooth surface. Advantages of airpolishers are rapid removal of tooth deposits, less invoked hypersensitivity, less operator fatigue, and improved access to pits and fissures ${ }^{5}$.

The purpose of this study was to investigate the effect of different air-polishing powders on the color stability of different types of composite resin restorative materials. The research hypothesis was that color stability of the composite resins is affected by the type of composite and the airpolishing powders.

\section{MATERIAL AND METHODS}

In the present study 7 composite resin restorative materials were investigated. The composite resins used in this study are shown in Figure 1. Thirty cylindrical specimens $(15 \times 2 \mathrm{~mm})$ were prepared for each of the 7 composite resin restorative materials using a brass mold. The materials were handled and polymerized according to the manufacturers' instructions. Light-polymerized specimens were polymerized using a halogen lamp (Astralis 3, Ivoclar-Vivadent, Schaan, Liechtenstein) with a light intensity of $400 \mathrm{~mW} / \mathrm{cm}^{2}$ for $20 \mathrm{~s}$ and with the light tip approximately $1 \mathrm{~mm}$ away from the specimens for both sides. Both sides of the specimens were wet-ground with 1000-grit silicon carbide abrasive paper for $10 \mathrm{~s}$, on a $300 \mathrm{rpm}$ grinding machine (Buehler Metaserv, Buehler, Germany). All specimens were polished with a series of $12.7-\mathrm{mm}-$ diameter aluminum oxide polishing discs (SofLex; 3M ESPE, St. Paul, MN, USA) with an electric handpiece (K10; Kavo, Leutkirch, Germany) at a speed of $10,000 \mathrm{rpm}$ for $10 \mathrm{~s}$ with coarse and medium discs and at a speed of 30,000 rpm for $10 \mathrm{~s}$ with fine and superfine discs according to manufacturer's directions. The specimens were stored for $24 \mathrm{~h}$ in distilled water at $37^{\circ} \mathrm{C}$ prior to subjecting them to air-powder application.

The prepared specimens of each composite resin were randomly divided into three groups of ten specimens each, for control (Group-C) and two different air-powder applications (Group-CP: Cavitron Prophy-Jet, Dentsply, Konstanz, Germany; Group-PS: ProSmile prophylaxis powder, Sirona Dental Systems GmbH, Bensheim, Germany). A standard air-polishing unit (ProSmile Handly, Sirona Dental Systems $\mathrm{GmbH}$ ) was used for this investigation and installed according to the manufacturer's instructions. For group $\mathrm{CP}$, the powder chamber of the air-polishing unit was filled to a maximum with Cavitron Prophy-Jet containing sodium bicarbonate and specimens were airpowdered for $10 \mathrm{~s}$ at 4-bar pressure. The distance of the spray nosel from the composite resin surface was approximately $10 \mathrm{~mm}$ and angulation of the nosel to the specimens was $90^{\circ}$. For Group-PS, the specimens were air-powdered with ProSmile prophylaxis powder containing sodium bicarbonate, calcium phosphate, and colloidal anhydrous silica described as Group-CP. All specimens were washed with tap water for 1 minute, ultrasonically cleaned in a water bath for $10 \mathrm{~min}$.

Baseline color measurement of all specimens was recorded before exposure to staining agent with a colorimeter (Minolta CR-300; Minolta Co, Osaka, Japan) using CIE (Commission Internationale de

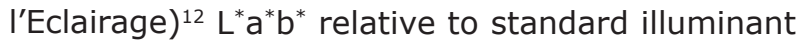
against a white background. $L^{*}$ refers to the 


\begin{tabular}{|c|c|c|c|c|c|}
\hline Product & Manufacturer & $\begin{array}{c}\text { LOT } \\
\text { Number }\end{array}$ & Matrix & Filler Size $(\mu)$ & $\begin{array}{c}\text { Filler } \\
\text { Weight (\%) }\end{array}$ \\
\hline $\begin{array}{l}\text { Aelite Aesthetic } \\
\text { Enamel } \\
\text { (Reinforced } \\
\text { Nanofil } \\
\text { Composite) }\end{array}$ & $\begin{array}{c}\text { Bisco, } \\
\text { Inc.,Schaumburg, } \\
\text { IL, USA }\end{array}$ & 800002171 & $\begin{array}{c}\text { Ethoxylated Bis-GMA, } \\
\text { Bis-GMA }\end{array}$ & $\begin{array}{c}\text { Glass Filler } \\
\text { Amorphous Silica } \\
0.04-5.0 \mu \mathrm{m}\end{array}$ & 73 \\
\hline $\begin{array}{l}\text { Filtek Silorane } \\
\text { (Silorane resin) }\end{array}$ & $\begin{array}{l}\text { 3M ESPE, St. } \\
\text { Paul, MN, USA }\end{array}$ & 7AJ & $\begin{array}{c}\text { Silorane } \\
\text { (3,4-epoxycyclohexylethylcyclo- } \\
\text { polymethylsiloxane, bis- } \\
\text { 3,4-epoxycyclohexylethyl- } \\
\text { phenylmethylsilane) }\end{array}$ & $\begin{array}{c}\text { Silicon dioxide, } \\
\text { ytterbium trifluoride } \\
0.1-2.0 \mu \mathrm{m}\end{array}$ & 76 \\
\hline $\begin{array}{c}\text { Filtek Z250 } \\
\text { (micro-hybrid/ } \\
\text { hybrid) }\end{array}$ & $\begin{array}{l}\text { 3M ESPE, St. } \\
\text { Paul, MN, USA }\end{array}$ & 7AK & Bis-GMA, UDMA, Bis-EMA & $\begin{array}{l}\text { Zirconia/silica } \\
0.01 \text { to } 3.5 \mu \mathrm{m}\end{array}$ & 78 \\
\hline $\begin{array}{c}\text { Quixfil } \\
\text { (micro-hybrid/ } \\
\text { hybrid) }\end{array}$ & $\begin{array}{l}\text { Dentsply, } \\
\text { DeTrey GmbH, } \\
\text { Konstanz, } \\
\text { Germany }\end{array}$ & 611000259 & $\begin{array}{c}\text { ethoxylated bisphenol- } \\
\text { A-dimethacrylate } \\
\text { (Bis-EMA), UDMA } \\
\text { TEGDMA } \\
\text { trimethylolpropane } \\
\text { trimethacrylate (TMPTMA) }\end{array}$ & $\begin{array}{c}\text { Glass } \\
1 \mu \mathrm{m}-10 \mu \mathrm{m}\end{array}$ & 86 \\
\hline $\begin{array}{l}\text { CeramX mono } \\
\text { (Nanohybrid) }\end{array}$ & $\begin{array}{l}\text { Dentsply, } \\
\text { DeTrey GmbH, } \\
\text { Konstanz, } \\
\text { Germany }\end{array}$ & 708000501 & $\begin{array}{c}\text { Bis-GMA, TGDMA, } \\
\text { UDMA }\end{array}$ & $\begin{array}{c}\text { Glass filler size } \\
\text { (mean) } \mu \mathrm{m} 1.1-1.5 \\
\text { Nano filler size (mean) } \\
10 \mathrm{~nm} \\
\text { Nano particle size } \\
\text { (mean) } 2.3 \mathrm{~nm}\end{array}$ & 76 \\
\hline $\begin{array}{c}\text { Grandio } \\
\text { (Nanohybrid) }\end{array}$ & $\begin{array}{c}\text { Voco, Cuxhaven, } \\
\text { Germany }\end{array}$ & 771060 & $\begin{array}{l}\text { Bis-GMA, } \\
\text { TGDMA, } \\
\text { UDMA }\end{array}$ & $\begin{array}{c}\text { Glass-ceramic } \\
\text { microfillers }(1 \mu \mathrm{m}) \\
\mathrm{SiO}_{2} \text { nanofillers }(20-60 \\
\mathrm{nm})\end{array}$ & 87 \\
\hline $\begin{array}{c}\text { IntenS } \\
\text { (micro-hybrid/ } \\
\text { hybrid) }\end{array}$ & $\begin{array}{c}\text { Ivoclar Vivadent, } \\
\text { Schaan, } \\
\text { Liechtenstein }\end{array}$ & H29977 & $\begin{array}{l}\text { Bis-GMA, } \\
\text { UDMA, } \\
\text { Bis-EMA }\end{array}$ & $\begin{array}{c}\text { Barium glass, } \\
\text { ytterbium trifluoride } \\
0.2-7.0 \mu \mathrm{m}\end{array}$ & 74 \\
\hline
\end{tabular}

Figure 1- Composite resins used in the study

lightness coordinate, and with value ranges from zero (black) to 100 (white). The values, $a^{*}$ and $b^{*}$ are chromaticity coordinates in the red-green axis and the yellow-blue axis, respectively. Positive $a^{*}$ values indicate a shift to red, and negative values indicate a shift to green. Similarly, positive $b^{*}$ values indicate the yellow color range, and negative values indicate the blue color range. Measurements were repeated 3 times for each specimen and the mean values of the $L^{*}, a^{*}$, and $b^{*}$ data were calculated. After baseline color measurements were made, specimens were stored in $100 \mathrm{~mL}$ of coffee (Nescafe Classic; Nestlé Suisse SA, Vevey, Switzerland) for $24 \mathrm{~h}$ at $37^{\circ} \mathrm{C}$. The coffee $(3.6 \mathrm{~g})$ was dissolved in $300 \mathrm{ml}$ of boiling distilled water according to manufacturer's suggested concentration. After 10 min of stirring, the solution was filtered through a filter paper.

After $24 \mathrm{~h}$ in the coffee solution, the specimens were rinsed with distilled water for $5 \mathrm{~min}$ and blotted dry with tissue paper before color measurement. At this point color readings were made using the colorimeter in the manner described for baseline readings. The calculation of the color variation $\Delta \mathrm{E}^{*}$ between the 2 color measurements (baseline and after $24 \mathrm{~h}$ storage) in the $3-\mathrm{d} \mathrm{L} \mathrm{L}^{*} \mathrm{a}^{*} \mathrm{~b}^{*}$ color space is as follows ${ }^{15,30}$.

$$
\Delta \mathrm{E}^{*}=\left[\left(\mathrm{L}_{1}{ }^{*}-\mathrm{L}_{0}{ }^{*}\right)^{2}+\left(\mathrm{a}_{1}{ }^{*}-\mathrm{a}_{0}{ }^{*}\right)^{2}+\left(\mathrm{b}_{1}{ }^{*}-\mathrm{b}_{0}{ }^{*}\right)^{2}\right]^{1 / 2}
$$

A two-way analysis of variance (ANOVA) using statistical software (SPSS for Windows, Version 12.0.1; SPSS Inc, Chicago, IL, USA) was used to evaluate the effect of the composite material and air-polishing powder on color stability, including the possibility of interactions between the two factors. 
Table 1- Mean (standard deviation) of color change $(\Delta \mathrm{E})$ and differences between groups

\begin{tabular}{lccccccc}
\hline \multicolumn{7}{c}{ Composite Resins } \\
\hline Group-C & $2.02(0.27)$ & $2.07(0.49)$ & $2.77(0.33)$ & $2.89(0.37)$ & $2.95(0.43)$ & $3.28(0.28)$ & $6.37(0.63)$ \\
Group-CP & $2.47(0.18)$ & $3.27(0.39)$ & $3.89(0.40)$ & $3.77(0.22)$ & $4.05(0.45)$ & $4.55(0.56)$ & $8.36(0.70)$ \\
Group-PS & $2.64(0.24)$ & $3.60(0.33)$ & $3.93(0.62)$ & $4.30(0.90)$ & $4.73(0.60)$ & $5.59(0.72)$ & $8.90(0.61)$ \\
Total & $2.38(0.35)$ & $2.98(0.78)$ & $3.53(0.71)$ & $3.65(0.81)$ & $3.91(0.89)$ & $4.47(1.10)$ & $7.88(1.27)$ \\
\hline
\end{tabular}

Vertical and horizontal lines connect groups that are not significantly different $(p>0.05)$

C-control; CP-Cavitron Prophy-Jet; PS- Sirona ProSmile Prophylaxis Powder

The means were then compared by Tukey's Honestly Significant Difference (HSD) test $(\alpha=0.05)$.

\section{RESULTS}

According to the 2-way ANOVA results, composite resin restorative materials, air-polishing powders, and their interaction were statistically significant $(\mathrm{p}<0.05)$. Mean $\Delta \mathrm{E}^{*}$ values, standard deviations (SD) of color differences, and group differences of the composite resin restorative materials are listed in Table 1.

For Aelite Aesthetic Enemal, Filtek Z250, Grandio, CeramX Mono, and Quixfil, no significant difference was observed between Group-PS and Group-CP ( $p>0.05)$ and these groups demonstrated the highest $\Delta \mathrm{E}^{*}$ values. The lowest $\Delta \mathrm{E}^{*}$ values were observed in Group-C for above composite resin groups.

For Filtek Silorane and IntenS composite resin restorative materials, the highest $\Delta \mathrm{E}^{*}$ values were observed in Group-PS. Group-CP was shown statistically significant lower $\Delta \mathrm{E}^{*}$ values than GroupPS and higher $\Delta \mathrm{E}^{*}$ values than Group-C. The lowest $\Delta \mathrm{E}^{*}$ values for these composite resin groups were observed in Group-C $(p<0.05)$.

When comparing the 7 different composite resin restorative materials, Aelite Aesthetic Enemal demonstrated statistically significantly less $\Delta \mathrm{E}^{*}$ values than the other composite resin tested $(p<0.05)$. No significant difference was observed among Grandio, Ceram X Mono, and Filtek Silorane $(p=0.055)$. The highest $\Delta E^{*}$ values were observed in Quixfil $(p<0.05)$.

\section{DISCUSSION}

On the basis of these data, the hypothesis set as the premises of this study is accepted. Different air-polishing powders affected the color stability of composite resin restorative materials. Although, new composites integrating nanofiller technology are being introduced into clinical practice to achieve better polishability and wear resistance, their properties, surface and color changes occurring after air-polishing are still unknown.

The CIE L*a*b* system for measuring chromacity was chosen to record color differences because it is well suited for determination of small color differences ${ }^{16,18}$. The use of the CIE L*a*b* system is also commonly used in dentistry because $L^{*}$, $a^{*}$, and $b^{*}$ are evenly distributed in a perceptual color space.

Discoloration of tooth-colored, resin-based materials may be caused by intrinsic and extrinsic factors. The intrinsic factors involve the discoloration of the resin material itself, such as the alteration of the resin matrix and of the interface of matrix and fillers. Every component may contribute to this phenomenon. Extrinsic factors for discoloration include staining by adsorption or absorption of colorants as a result of contamination from exogenous sources ${ }^{20}$. The staining of polymeric materials by colored solutions, coffee and tea and beverages has been reported ${ }^{8}$. In this study, coffee was used as a colorant agent because of its frequent consumption in daily life. Before the baseline color measurement, specimens were stored in distilled water at $37^{\circ} \mathrm{C}$ for $24 \mathrm{~h}$. The rehydration simulated the first day of service for restorations in the oral environment. It is known that the type of materials used in this study imbibe most of the water during the first day of immersion².

Staining of composite resin surface is a complex phenomenon that can involve several mechanisms. Finishing and polishing procedures may influence surface smoothness, which is related to early discoloration and rough surfaces mechanically retain surface stains more than smooth surfaces ${ }^{8,26}$. Smoother composite resin surfaces are obtained when the material was cured against a polyester matrix ${ }^{32}$. Despite careful placement of the matrix, removing excess material and recountouring restorations is often clinically necessary. This requires some degree of finishing and polishing, which may alter the smoothness obtained with a matrix $^{32}$. In addition, according to the results of previous studies Mylar group showed the highest color change as the oxygen-inhibited layer is not removed in this group leaving an uncured superficial 
layer of composite which is prone to discoloration ${ }^{9,21}$.

Finishing instruments have been designed to produce a smooth surface on dental restorative materials. The aluminum oxide discs have been shown to produce better surface smoothness because they do not displace the composite fillers ${ }^{4}$. Berastegui, et al. ${ }^{3}$ (1992) reported that the fillers in microfilled composite resins are so small that their stiffness is reduced and therefore the aluminum oxide discs are best recommended because their malleability promotes a homogeneous abrasion of the fillers and the resin matrix. The finding of the previous study showed that flexible aluminum oxide discs (Sof-Lex) yielded the lowest Ra values for microfilled, hybrid, and packable composite resins ${ }^{1}$. For these reasons, all the specimens were polished with a series of Sof-Lex aluminum oxide polishing discs in the present study. $A \Delta \mathrm{E}^{*}$ value of 3.7 or less is considered to be clinically acceptable ${ }^{14,18}$. Except for Quixfil, all control groups of composite resins that were polished with Sof-Lex exhibited clinically acceptable $\Delta \mathrm{E}$ values $(<3.7)$ in the present study. Group-C of Quixfil composite resin exhibited higher $\Delta E$ value than 3.7. The reason of this may be filler weight and filler size of Quixfil is higher than the other composite resins tested (Figure I). In addition, Group-CP and Group-PS of Grandio, CeramX Mono, Filtek Silorane, and IntenS composite resins exhibited higher $\Delta \mathrm{E}$ values than 3.7.

When comparing the 7 composite resin restorative materials, Intens exhibited higher mean $\Delta \mathrm{E}^{*}$ value than nanohybrid, nanofil, and silorane based restorative materials tested. The highest $\Delta \mathrm{E}^{*}$ values were observed in Quixfil composite resin restorative material $(p<0.05)$. Schwartz and Söderholm ${ }^{27}$ (2004) determined that a composite resin with finer filler particles has smaller interparticle spaces, but also a larger total filler surface area. They stated that, as a consequence of smaller interparticle spaces and larger filler surface area, diffusion occurs more slowly in the finer composites. Therefore, more water uptake and more discoloration caused by immersion in food dyes would have been expected if larger filler particles had been used. Staining is directly related to the resin phase of composites $^{23}$. Urethane dimethacrylate (UDMA) seems to be more stain resistant than bis-GMA ${ }^{16}$. The resin systems of Quixfil, CeramX mono, and Grandio consist of three primary components; bis-GMA, UDMA, and TEGDMA. However, the resin system of Filtek Z250, Aelite Aesthetic Enamel, and IntenS consist primarily of; bis-GMA, UDMA, and bis-EMA. In these restorative systems, the majority of TEGDMA, a somewhat hydrophilic monomer, has been replaced with a blend of UDMA and bis-EMA ${ }^{6}$. The low staining susceptibility of Z250 and Aelite Aesthetic Enamel may be related to a low water sorption rate due to the use of hydrophobic resins. On the other hand, silorane-based materials have shown good chemical stability when exposed to aqueous environments ${ }^{7}$, as well as lower watersorption, solubility and diffusion coefficient ${ }^{19}$, which could explain the higher stability of this material. Palin, et al. ${ }^{19}$ (2005) hypothesize that the increased synergism between filler particles and resin matrix, due to experimental silorane-based resin-composites' decreased viscosity and increased wettability of the new silanizing agent may be responsible for this reduction in water sorption and solubility. In the present study, Filtek Silorane exhibited average color change among the tested restorative materials and no significant difference was observed between nanohybrid composite resins and Filtek Silorane.

The effect of hygiene procedures on surface roughness was material dependent. Composites are biphasic, with fillers embedded in a resin/polymer matrix $^{31}$. During hygiene procedures, the matrix phase is preferentially removed ${ }^{11,25}$ as the abrasives employed in prophylaxis agents are harder than the resin matrix. These abrasives could even be similar in hardness to the fillers of some composite materials. As the resin matrix is selectively removed, filler particles are exposed, resulting in a rough surface ${ }^{25}$. Johnson, et al. ${ }^{13}$ (2004) stated that regardless of the polishing agent used, whether sodium bicarbonate or aluminum trihydroxide, the use of these agents should be avoided on dental restorative materials. Lubow and Cooley ${ }^{17}$ (1986) evaluated the effect of an air-polishing system that uses sodium bicarbonate powder on the surface characteristics of various restorative materials. They found that the composite resins underwent the greatest change in roughness ${ }^{17}$. In the present study, air-polishing applications increased the color change for all the composite resin restorative materials tested. Except Aelite Aesthetic Enamel and Filtek Z250, $\Delta \mathrm{E}^{*}$ values of Group-CP and Group-PS for all the composite resin restorative materials tested were observed above the clinically acceptable $\Delta E$ value. When compared two different air-polishing powders, ProSmile prophylaxis powder exhibited higher $\Delta \mathrm{E}^{*}$ values than Cavitron ProphyJet. The reason of this may be difference in contents of these two different air-polishing powders. While Cavitron Prophy-Jet contains sodium bicarbonate, ProSmile prophylaxis powder contains calcium phosphate and colloidal anhydrous silica in addition to sodium bicarbonate.

The present study has several limitations. The specimen surfaces were flat, whereas, clinically, composite resin restorations have an irregular shape with convex and concave surfaces. Furthermore, the application of surface finishing procedure used in this study may be difficult to perform clinically. 
However, there is limited published information as to how storage conditions reflect the clinical situation. The solution used in this study does not consider all substances to which composite restorative materials may be exposed. In the present study, two different air-polishing powder which have different contents were evaluated and the specimens were air-powdered for $10 \mathrm{~s}$ at 4-bar pressure. The distance of the spray nosel from the composite resin surface was approximately 10 $\mathrm{mm}$ and angulation of the nosel to the specimens was $90^{\circ}$. The effects of different application times, pressures, distances and angulations of nosel on the color stability of different restorative materials will be carried out in future studies.

\section{CONCLUSION}

Within the limitations of the present study, the following conclusions can be drawn:

1- Except for Quixfil, all control groups of composite resins that were polished Sof-Lex exhibited clinically acceptable $\Delta \mathrm{E}$ values $(<3.7)$;

2- The highest color change average was recorded for Quixfil, while the lowest color change was recorded for Aelite Aesthetic Enamel;

3- Filtek Silorane exhibited average color change among restorative materials tested and no significant difference was observed between nanohybrid composite resins and Filtek Silorane;

4- Comparing the air-polishing powders tested, ProSmile prophylaxis powder exhibited higher $\Delta \mathrm{E}$ values than Cavitron Prophy-Jet;

5- Air-polishing applications increased the color change for all composite resin restorative materials tested. Composite restorations may require repolishing after air-polishing.

\section{REFERENCES}

1- Barbosa SH, Zanata RL, Navarro MFL, Nunes OB. Effect of different finishing and polishing techniques on the surface roughness of microfilled, hybrid and packable composite resins. Braz Dent J. 2005;16:39-44.

2- Benington IC, Cunningham JL. Sorption determination of hollow VLC resin obturators. J Dent. 1991;19:124-6.

3- Berastegui E, Canalda C, Brau E, Miquel C. Surface roughness of finished composite resins. J Prosthet Dent. 1992;68:742-9.

4- Bouvier D, Duprez JP, Lissac M. Comparative evaluation of polishing systems on the surface of three aesthetic materials. J Oral Rehabil. 1997;24:888-94.

5- Brown DM, Barnhart RC. A scientific foundation for clinical use of air-polishing systems. Part I. A review of the literature. J Prac Hygn. 1995;4:36-40.

6- Choi KK, Ferracane JL, Hilton TJ, Charlton D. Properties of packable composites. J Esthet Dent. 2000;12:216-26.

7- Eick JD, Smith RE, Pinzino CS, Kostoryz EL. Stability of silorane dental monomers in aqueous systems. J Dent. 2006;34:405-10. 8- Ertas E, Guler AU, Yucel AC, Köprülü H, Guler E. Color stability of resin composites after immersed in different drinks. Dent Mater J. $2006 ; 25: 371-6$.
9- Gordan VV, Patel SB, Barrett AA, Shen C. Effect of surface finishing and storage media on bi-axial flexure strength and microhardness of resin-based composite. Oper Dent. 2003;28:560-7.

10- Guggenberger R, Weinmann W. Exploring beyond methacrylates. Am J Dent. 2000;13:82-4.

11- Gutmann MS, Marker VA, Gutmann JL. Restoration surface roughness after air-powder polishing. Am J Dent. 1993;6:99-102. 12- International Commission on Illumination. Colorimetry: official recommendations of the International Commission on Illumination. $2^{\text {nd }}$ ed. Vienna: Bureau Central de la CIE; 1986.

13- Johnson WW, Barnes CM, Covey DA, Walker MP, Ross JAR. The effects of a commercial aluminum airpolishing powder on dental restorative materials. J Prosthodont. 2004;13:166-72.

14- Johnston WM, Kao EC. Assessment of appearance match by visual observation and clinical colorimetry. J Dent Res. 1989;68:819-22.

15- Judd DB, Wyszecki G. Color in business, science and industry. New York: Wiley; 1975. p. 5-90.

16- Khokhar ZA, Razzoog ME, Yaman P. Color stability of restorative resins. Quintessence Int. 1991;22:733-7.

17- Lubow RM, Cooley RL. Effect of an air-powder abrasive instrument on restorative materials. J Prosthet Dent. 1986;55:4625.

18- Okubo SR, Kanawati A, Richards MW, Childress S. Evaluation of visual and instrument shade matching. J Prosthet Dent. 1998;80:642-8.

19- Palin WM, Fleming GJP, Burke FJT, Marquis PM, Randall RC. The influence of short and medium-term water immersion on the hydrolytic stability of novel low-shrink dental composites. Dent Mater. 2005;21:852-63.

20- Paravina RD, Powers JM. Esthetic color training in dentistry. St. Louis: Mosby; 2004. p. 69-123.

21- Patel SB, Gordan VV, Barrett AA, Shen C. The effect of surface finishing and storage solutions on the color stability of resin-based composites. J Am Dent Assoc. 2004;135:587-94.

22- Powers JM, Sakaguchi RL. Craig's restorative dental materials $12^{\text {th }}$ ed. St. Louis: Mosby; 2006. p.189-212.

23- Reis AF, Giannini M, Lovadino JR, Ambrosano GM. Effects of various finishing systems on the surface roughness and staining susceptibility of packable composite resins. Dent Mater. 2003;19:12-8.

24- Ritter AV. Direct resin-based composites: current recommendations for optimal clinical results. Compend Contin Educ Dent. 2005;26:481-2,484-90.

25- Roulet JF, Roulet-Mehrens TK. The surface roughness of restorative materials and dental tissues after polishing with prophylaxis and polishing pastes. J Periodontol. 1982;53:257-66. 26- Saraç D, Saraç YS, Kulunk S, Ural C, Kulunk T. The effect of polishing techniques on the surface roughness and color change of composite resins. J Prosthet Dent. 2006;96:33-40.

27- Schwartz JI, Söderholm KJM. Effects of filler size, water, and alcohol on hardness and laboratory wear of dental composites. Acta Odontol Scand. 2004;62:102-6.

28- Seghi RR, Gritz MD, Kim J. Colorimetric changes in composites resulting from visible-light-initiated polymerization. Dent Mater. 1990;6:133-7.

29- Shick RA. Maintenance phase of periodontal therapy. J Periodontol. 1981;52:576-83.

30- Wyszechi G, Stiles WS. Color science: concepts and methods, quantitative data and formulas. $2^{\text {nd }}$ ed. New York: John Wiley; 1982. p.13-116.

31- Yap AU, Chew CL, Teoh SH, Ong LF. Influence of contact stress on OCA wear of composite restoratives. Oper Dent. 2001;26:134-44.

32- Yap AU, Mok BY. Surface finish of a new hybrid aesthetic restorative material. Oper Dent. 2002;27:161-6. 